\title{
Region-specific depletion of synaptic mitochondria in the brains of patients with Alzheimer's disease
}

\author{
Eleanor K. Pickett ${ }^{1}$. Jamie Rose ${ }^{1}$ - Caoimhe McCrory ${ }^{1}$. Chris-Anne McKenzie ${ }^{2}$ - Declan King ${ }^{1}$ - Colin Smith ${ }^{2}$. \\ Thomas H. Gillingwater ${ }^{1}$. Christopher M. Henstridge ${ }^{1} \cdot$ Tara L. Spires-Jones $^{1}$ (i)
}

Received: 20 July 2018 / Revised: 22 August 2018 / Accepted: 22 August 2018 / Published online: 6 September 2018

(c) The Author(s) 2018

\begin{abstract}
Of all of the neuropathological changes observed in Alzheimer's disease (AD), the loss of synapses correlates most strongly with cognitive decline. The precise mechanisms of synapse degeneration in AD remain unclear, although strong evidence indicates that pathological forms of both amyloid beta and tau contribute to synaptic dysfunction and loss. Synaptic mitochondria play a potentially important role in synapse degeneration in AD. Many studies in model systems indicate that amyloid beta and tau both impair mitochondrial function and impair transport of mitochondria to synapses. To date, much less is known about whether synaptic mitochondria are affected in human AD brain. Here, we used transmission electron microscopy to examine synapses and synaptic mitochondria in two cortical regions (BA41/42 and BA46) from eight AD and nine control cases. In this study, we observed 3000 synapses and find region-specific differences in synaptic mitochondria in $\mathrm{AD}$ cases compared to controls. In BA41/42, we observe a fourfold reduction in the proportion of presynaptic terminals that contain multiple mitochondria profiles in $\mathrm{AD}$. We also observe ultrastructural changes including abnormal mitochondrial morphology, the presence of multivesicular bodies in synapses, and reduced synapse apposition length near plaques in AD. Together, our data show region-specific changes in synaptic mitochondria in AD and support the idea that the transport of mitochondria to presynaptic terminals or synaptic mitochondrial dynamics may be altered in AD.
\end{abstract}

Keywords Alzheimer's disease $\cdot$ Synapses $\cdot$ Mitochondria $\cdot$ Electron microscopy

\section{Introduction}

Alzheimer's disease (AD) is the most common cause of dementia affecting around 30 million people worldwide. There are currently no disease-modifying treatments for $\mathrm{AD}$, making understanding the underlying mechanisms of neurodegeneration a high research priority. Pathologically, the disease is defined by brain atrophy and the accumulation

Electronic supplementary material The online version of this article (https://doi.org/10.1007/s00401-018-1903-2) contains supplementary material, which is available to authorized users.

Tara L. Spires-Jones

Tara.Spires-Jones@ed.ac.uk

1 Centre for Discovery Brain Sciences, UK Dementia Research Institute, The University of Edinburgh, 1 George Square, Edinburgh EH8 9JZ, UK

2 Centre for Clinical Brain Sciences, Edinburgh Brain and Tissue Bank, The University of Edinburgh, Edinburgh, UK of amyloid beta in extracellular plaques and tau in neurofibrillary tangles [54]. The brain atrophy comprises loss of neurons, white matter and synapses.

Synapse loss correlates strongly with cognitive decline in $\mathrm{AD}$ when measured by counting synaptic profiles with electron microscopy (EM) or by measuring synaptic protein levels $[10,11,60]$. Both $A \beta$ and tau contribute to synapse dysfunction and degeneration in $\mathrm{AD}$ model systems and are observed in synapses in human AD brain [31, 40, 46, 47, 55, 63]. However, the causes of synapse dysfunction and degeneration in the human brain remain largely unknown. Synaptic mitochondria are potentially important players in synapse degeneration in AD brain. Damage to synaptic mitochondria or failure to transport enough mitochondria to synapses could both impair function and lead to synapse collapse.

The role of mitochondria in metabolism is crucial for providing the necessary energy required for neurotransmitter release at the presynapse [62]. ATP generation is mediated through the electron transport chain (ETC), consisting of 
five protein complexes undergoing sequential redox reactions, which culminate in the production of ATP. Importantly, recent work shows that synaptic mitochondria have distinct morphologies and proteomic profiles compared to non-synaptic mitochondria, which may make synapses particularly vulnerable to degeneration [20]. In AD models, $\mathrm{A} \beta$ preferentially blocks complex IV of the ETC $[22,30]$, whereas tau impairs complex I [8]. By targeting different components of the same system, $A \beta$ and tau amplify one another's toxic effects [27, 51].

Since the synapse is a site of high-energy demand, it is necessary for mitochondria to be trafficked to this location. Tau plays a crucial role in binding and stabilising microtubules required for this anterograde transport of mitochondria [15]. It has been suggested that pathological tau may interfere with this trafficking process resulting in impaired anterograde transport of cargo [28, 33]. Both in vitro and in vivo models have shown that the overexpression of tau inhibits anterograde mitochondrial transport and disrupts mitochondrial distribution in neurites, resulting in perinuclear clumping in the soma [32, 57]. In addition to tau-associated transport deficits, oligomeric $\mathrm{A} \beta$ has also been implicated in the impairment of mitochondrial movements in hippocampal cultures $[5,9,52,53]$. Considering that both tau and $A \beta$ have been implicated in disrupted anterograde mitochondrial transport, depletion of mitochondria at the synapse may be a synergistic mechanism contributing to synaptotoxicity. Data from human $\mathrm{AD}$ brain demonstrate that mitochondria accumulate in dystrophic neurites [56], which implies that they may be stuck in dystrophies and prevented from reaching synaptic terminals. To formally test the hypothesis that the presence of mitochondria in synaptic terminals is altered in $\mathrm{AD}$, we used transmission EM to quantify synaptic mitochondria in two cortical regions-BA46 and BA41/42. Furthermore, we examined ultrastructural features of synapses in these brain regions. We find a reduction in the percentage of presynaptic terminals containing multiple mitochondria in BA41/42 of $\mathrm{AD}$ patients compared to control subjects, and we observe abnormal mitochondrial morphology in synapses in AD but not control cases. Our results indicate that synaptic mitochondria are affected in a region-specific manner in Alzheimer's disease, which may impair synaptic function and cognition.

\section{Materials and methods}

\section{Post-mortem analysis}

Tissue from eight clinically and pathologically diagnosed Alzheimer's disease donors and nine control donors were used for this study (details in Online Resource 1). Use of human tissue for post-mortem studies has been reviewed and approved by the Edinburgh Brain Bank ethics committee and the ACCORD medical research ethics committee (approval HV-15-016; ACCORD is the Academic and Clinical Central Office for Research and Development, a joint office of the University of Edinburgh and NHS Lothian). The Edinburgh Brain Bank is a Medical Research Council funded facility with research ethics committee (REC) approval 16/ES/0084.

\section{Tissue preparation}

At post-mortem, the brain was removed and cut into coronal slices. Regions of interest were then dissected from each coronal slice. Samples from one hemisphere were dissected into smaller segments and processed for electron microscopy as described previously [29]. Fresh post-mortem samples from BA46 (dorsolateral prefrontal cortex) and BA41/42 (anterior/posterior transverse temporal cortex) were trimmed into small cortical blocks containing the six cortical layers and fixed in $4 \%$ paraformaldehyde and $2.5 \%$ glutaraldehyde in $0.1 \mathrm{M}$ phosphate buffer (PB) for $48 \mathrm{~h}$. Fixed tissue blocks were washed twice in $0.1 \mathrm{M} \mathrm{PB}$ and were exposed to osmium tetroxide (1\% in $0.1 \mathrm{M} \mathrm{PB}$ ) for $30 \mathrm{~min}$ (protected from light). Samples were washed twice for $15 \mathrm{~min}$ in $0.1 \mathrm{M} \mathrm{PB}$ and three times in previously boiled $\mathrm{ddH}_{2} \mathrm{O}$. Tissue blocks were then dehydrated for $15 \mathrm{~min}$ in $50 \%$ ethanol followed by exposure to $1 \%$ uranyl acetate in $70 \%$ ethanol for $40 \mathrm{~min}$ in the dark. Samples were further dehydrated in an ascending series of ethanol $(95 \%, 100 \%, 100 \%)$ and propylene oxide before storage in Durcupan resin overnight at room temperature. Samples were embedded in Durcupan resin and allowed to polymerise for $48 \mathrm{~h}$ at $60{ }^{\circ} \mathrm{C}$.

\section{Tissue sectioning and imaging}

Resin-embedded tissue blocks were cut into 70-nm-thick sections using an ultracut microtome (Leica) equipped with a Jumbo Histo Diamond Knife (Diatome, Hatfield, PA, USA) and collected onto copper formvar-coated grids. Grids were stained with lead citrate in a $\mathrm{CO}_{2}$-free environment for $2 \mathrm{~min}$ before imaging on a JEOL JEM-1400 Plus transmission electron microscope (TEM). For synapse analysis, an average of 50 images per case was taken at $6000 \times$ magnification in a systematic, random fashion from BA46 and BA41/42 (Fig. 1). Exclusion criteria for sampling images included the presence of a nucleus in the entire field of view, no synapses present in the field of view or the presence of an $A \beta$ plaque or NFT in the entire field of view. TEM images were coded for blind analysis. Synapses were defined by a presynaptic terminal containing at least three synaptic vesicles adjacent to an electron-dense post-synaptic density. Mitochondria were defined by the presence of internal cristae and a defined outer membrane. 100 synapses per case for each brain region (where available, please see Online Resource 

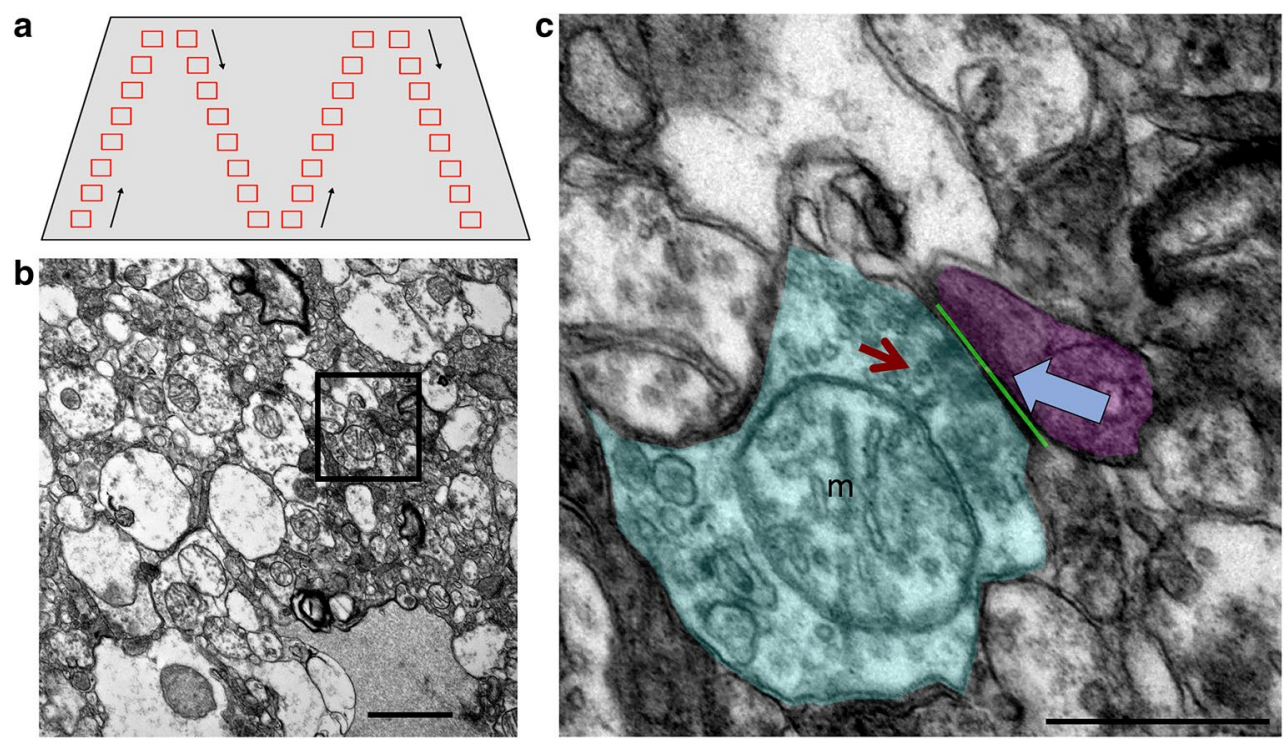

Fig. 1 EM Sampling. TEM images were taken throughout the neuropil in a systematic fashion to ensure sampling from the entire tissue block face without repeated sampling or bias (a). Images were taken at $\times 6000$ magnification $(\mathbf{b})$. Individual synapses (inset in $\mathbf{b}, \mathbf{c}$ ) were identified by the presence of at least three presynaptic vesicles (red arrow) and a clearly identifiable, electron-dense post-synaptic density (blue arrow). The presence of mitochondria (m) in the pre- (shaded cyan) or post-(shaded magenta) synaptic terminals was recorded and the length of the PSD opposed to the presynaptic active zone was measured (green line). Scale bars represent $1 \mu \mathrm{m}(\mathbf{b}), 500 \mathrm{~nm}(\mathbf{c})$
1) were analysed for a total of 3000 synapses analysed for the presence of mitochondria (individual or multiple) in the pre- or post-synapse and any unusual features in the synapse noted (abnormal mitochondrial morphology, presence of multivesicular bodies, or presence of fibrils). The length of the post-synaptic density opposing the presynaptic terminal was also measured (apposition length). Extra blocks from temporal, occipital, and frontal cortex were examined for plaques in three AD cases and all plaque-associated synapses pooled for apposition length measurements (80 synapses near plaques analysed). Single sections were imaged as opposed to reconstructing three-dimensional reconstructions of serial sections to allow imaging of large numbers of synapses. We have previously demonstrated that 2D EM quantification techniques performed on synapses, such as those used in our present study, generate near identical findings to parallel 3D quantification studies [19].

\section{Statistical analysis}

Images were analysed by an experimenter blind to diagnosis. For each variable, a single value was calculated per region per case. Statistics were calculated in SPSS and GraphPad Prism. Normality of the data was tested with a Shapiro-Wilk test. Normally, distributed data (apposition length, and percentages of pre- and post-synapses containing a single mitochondrion) were analysed by two-way ANOVA and Tukey's post hoc tests and are shown as mean and standard errors. Non-normally distributed data (percentages of pre- and post-synapses containing more than one mitochondria and percentage of post-synapses containing multivesicular bodies) were analysed with non-parametric Kruskal-Wallis tests and are shown as median and interquartile ranges.

\section{Results}

\section{Presynaptic terminals in AD superior temporal gyrus have fewer mitochondria than controls}

To test the hypothesis that mitochondrial localisation in synapses is affected in AD, synapses were analysed from AD and control brain samples using transmission electron microscopy (Fig. 1). Raw EM images are freely available from the University of Edinburgh Data Repository DataShare at https://doi.org/10.7488/ds/2417.

We systematically sampled cortex to analyse synaptic mitochondria in asymmetric synapses in two brain regions, superior temporal gyrus (BA41/42) and dorsolateral prefrontal cortex (BA46). These brain regions play an important role in memory encoding and recognition (BA46) and auditory working memory (BA41/42), which are disrupted in $\mathrm{AD}[2,58]$, and by the end stages of disease, both of these regions have substantial plaque and tangle pathology [54]. We observed mitochondria in a subset of pre- and post-synapses in both regions of AD and control brains (Fig. 2). Twoto threefold more presynaptic terminals contained mitochondria (ranging from 14 to $37 \%$ in AD cases and $22-45 \%$ in 

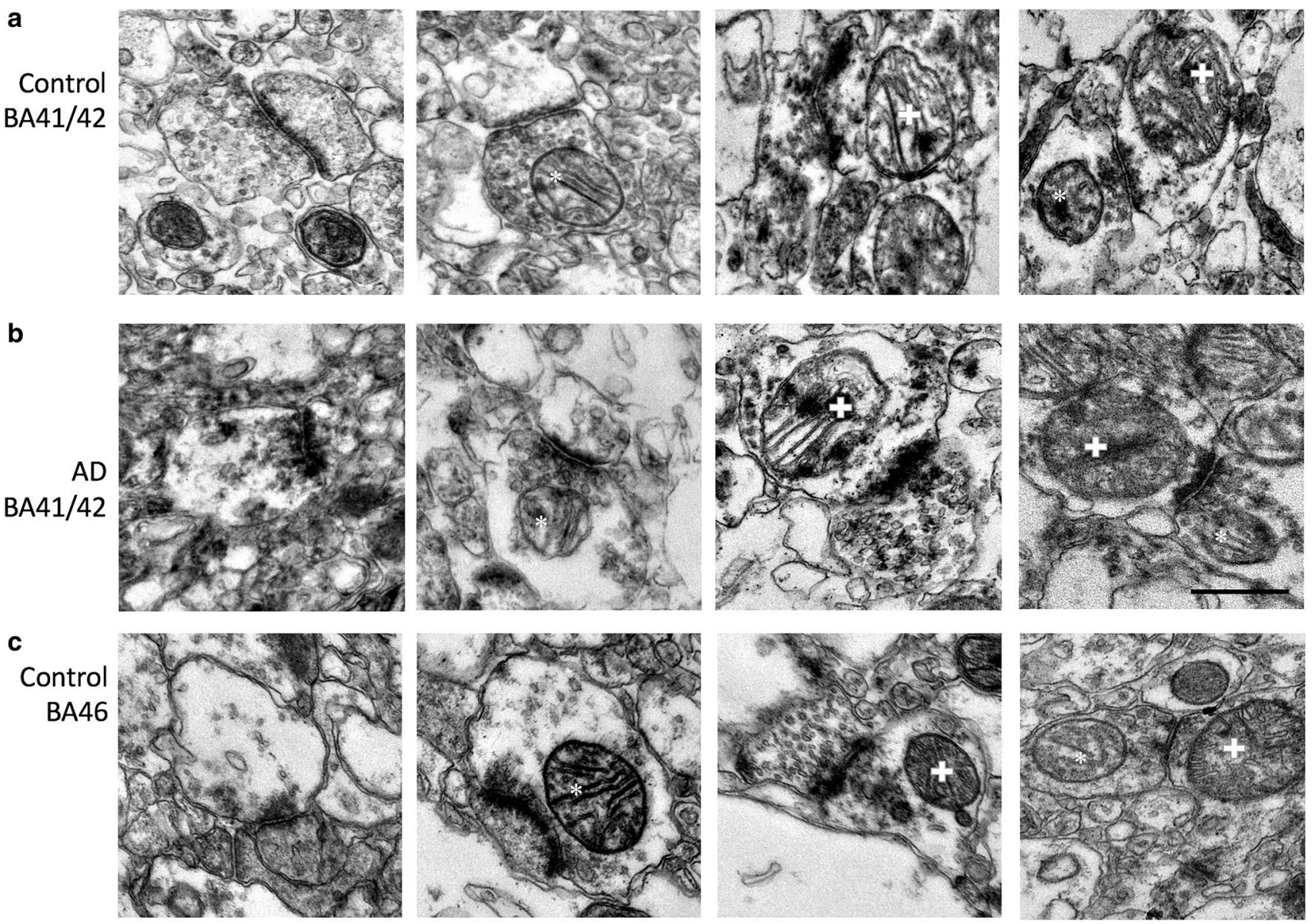

d
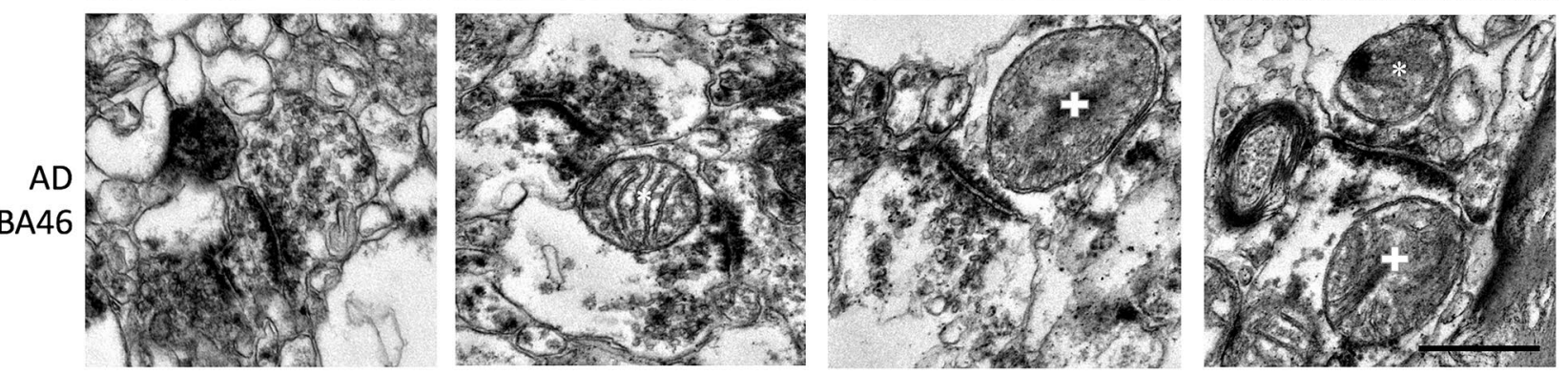

Fig. 2 Examples of synapses and synaptic mitochondria. Mitochondria were observed both in presynaptic terminals (asterisks) and post-synaptic terminals (crosses) in control and AD subjects in BA41/42 (a, b) and BA46 (c, d). Scale bar $500 \mathrm{~nm}$

controls) than post-synaptic terminals (ranging from 8 to $23 \%$ in $\mathrm{AD}$ cases and 5-17\% in controls). In both $\mathrm{AD}$ and control cases, the higher percentage in pre-synapses than in post-synapses was significant (two-way ANOVA effect of pre vs. post in $\operatorname{AD} F(1,26)=68.84, p<0.001$; in control $F(1,26)=105.3, p<0.001)$. Interestingly, there was a trend towards a region effect in the difference between pre- and post-synaptic mitochondria only in AD (two-way ANOVA effect of region in $\operatorname{AD~} F(1,26)=7.91, p=0.093$; control $F(1,26)=0.57, p=0.46)$. The presence of mitochondria in presynaptic terminals was lower in BA41/42 than in BA46 (Fig. 3a), whereas the percentage of post-synaptic profiles containing mitochondria did not differ by region or with disease (Fig. 3b). A small fraction (0-8\%) of synaptic terminals contained more than one mitochondrial profile. In BA41/42, AD cases had over fourfold fewer presynaptic terminals with multiple mitochondrial profiles than control synapses from the same region (Figs. 3c, 4a). The percentage of pre-synapses containing multiple mitochondria was not different between $\mathrm{AD}$ and control in BA46, indicating that transport of mitochondria to presynaptic terminals may be impaired in a region-specific manner.

To ensure the significant decrease in presynaptic terminals containing multiple mitochondria was not an artefact 
a

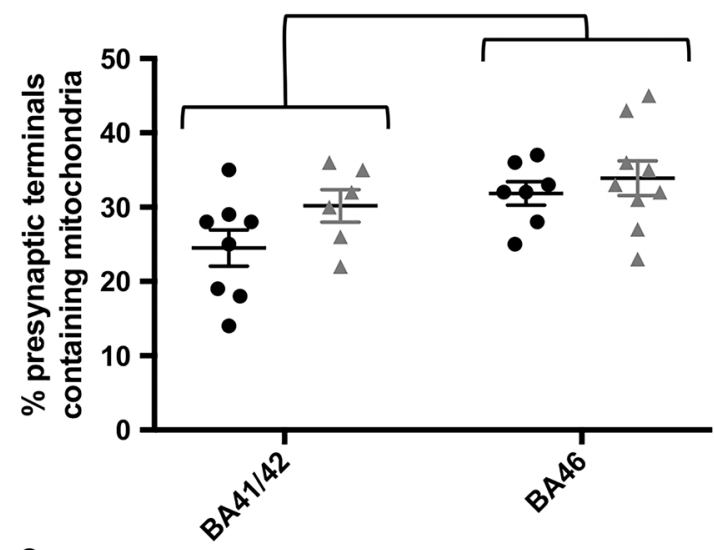

C

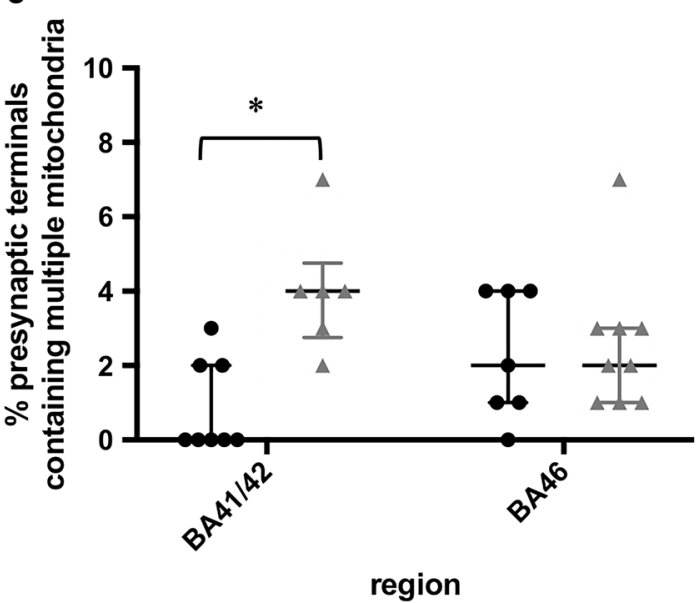

Fig. 3 Region-specific depletion of presynaptic mitochondria in AD. The percentage of presynaptic mitochondria is lower in BA41/42 than in BA46 (a, asterisk: two-way ANOVA effect of $F(1,26)=5.965$, $p=0.022$ ). There were no differences in region or disease condition in the percentage of post-synaptic terminals containing mitochondria (b). Presynaptic terminals containing more than one mitochon-

of post-mortem degradation, we ran correlation analyses to confirm that there is not an association of PMI or brain $\mathrm{pH}$ with this outcome measure. None of the measures of mitochondria in synapses correlated with $\mathrm{pH}$ or PMI in either AD or control groups. When considering all cases (AD and controls) together, there is a strong correlation $(r=-0.76, p<0.001)$ with disease status and \% presynaptic terminals containing multiple mitochondria in BA41/42 as would be expected from our significant difference found with ANOVA.

Multiple mitochondrial profiles in a single presynaptic bouton in the single-section images that we analysed for the 3000 synapses in the study could correspond to multiple mitochondria or to different parts of the same mitochondrion that has curved out of the plane of view. Three-dimensional reconstructions of two pre-synapses with multiple mitochondria show separate mitochondria b
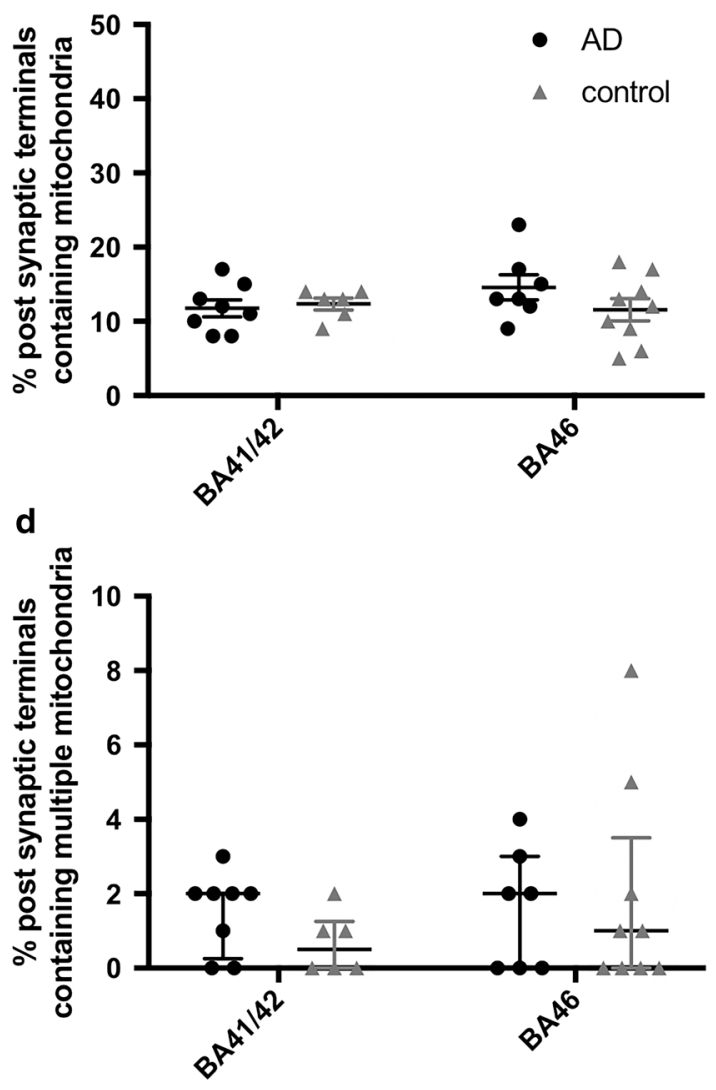

region

dria were over four times less common in presynaptic terminals of AD BA41/42 (c, asterisk: independent samples Kruskal-Wallis test, $p=0.004)$. Each data point shows the percentage for an individual case. Data are represented as mean and standard errors in $\mathbf{a}, \mathbf{b}$ and medians with interquartile ranges $(\mathbf{c}, \mathbf{d})$

in presynaptic terminals (Online Resource 2, Online Resource 3).

Along with the localisation of mitochondria to synapses, we examined the ultrastructure of synapses and synaptic mitochondria. We noted occasional abnormal mitochondrial morphology in AD cases (Fig. 4b) which may indicate mitochondrial dysfunction. Further, we observed accumulation of multivesicular bodies in post-synaptic terminals in BA41/42 of AD cases which was rare but exhibited a trend towards significance (Fig. 4c, d). Apposition length was not changed by region or diagnosis (Fig. 4e). Previous data using array tomography indicated synapse shrinkage near plaques [31]. We did not find enough plaques in the BA41/42 and BA46 samples examined in the systematic random fashion for the main study to compare synapses near and far from plaques. However, we screened blocks for plaques from temporal, frontal, and occipital cortices from three of the $\mathrm{AD}$ 


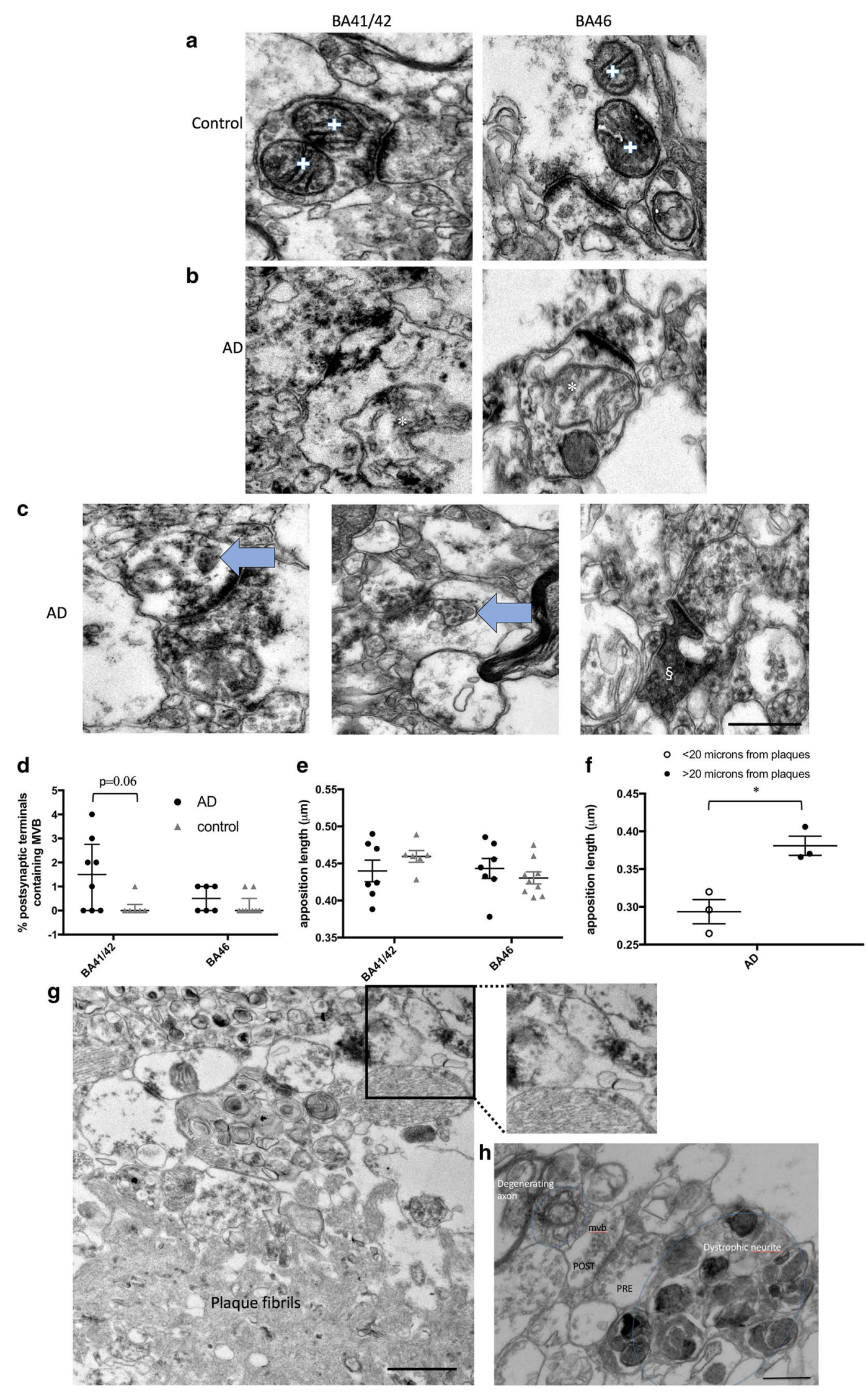


४Fig. 4 Changes in synaptic morphology in AD. In control cases, multiple mitochondrial profiles in individual pre-synapses were observed (a, crosses), while in AD cases, mitochondria with irregular profiles were observed in synapses (b, asterisks). Multivesicular bodies (MVB, arrows, c) were observed in a subset of post-synapses, and occasional dark degenerating spines $(\S, \mathbf{c})$ were observed in $\mathrm{AD}$ cortex. MVB appeared most often in AD BA41/42 synapses where there was a trend to increase compared to control (d, Kruskal-Wallis, $p=0.06$ ). Apposition length was unchanged in $\mathrm{AD}$ vs. controls in BA41/42 or BA46 (e). When more blocks were examined from temporal, frontal and occipital regions to find synapses near plaques $(\mathbf{f}, \mathbf{g})$ and the data combined, we observe significantly decreased apposition length in synapses near plaques compared to those far from plaques (f, asterisk: unpaired $t$ test with Welch correction, $t=4.28, p=0.01$ ). $\mathbf{g}$ An example of a small synapse near a plaque. $\mathbf{h}$ More detail around a plaque including a synapses (with pre- and post-synaptic terminals labelled, the post-synapse contains a MVB), a dystrophic neurite, and a degenerating axon. Data are shown as median with interquartile range. Scale bars represent $500 \mathrm{~nm}(\mathbf{a}-\mathbf{c}$, inset $\mathbf{g}, \mathbf{h}) ; 1000 \mathrm{~nm}$ (large panel $\mathbf{g}$ )

cases to find more plaques to allow investigation of apposition length of synapses near plaques. A total of 80 synapses near plaques and 219 synapses far from plaques in the same blocks were observed across the three AD cases examined. The average apposition length for each case near and far from plaques was calculated and found to be $23 \%$ smaller near plaques than far from plaques (Fig. 4f, g).

It is also worth noting that of the 3000 synapses systematically sampled in BA41/42 and BA46 and in the 80 synapses near plaques from all regions, we did not find any pre- or post-synaptic terminals containing fibrils, despite the clear appearance of plaque and tangle fibrils in AD cases (Fig. 5). In our previous studies, we detect a substantial proportion of synapses near plaques that are positive for oligomeric $A \beta$ using array tomography [31]. The current ultrastructural data indicate that these oligomers are not yet fibrillar.

\section{Discussion}

Proper synaptic function requires the recruitment of mitochondria to these specialised regions, where energy is in high demand, and elevated levels of calcium are generated in response to synaptic activity. To meet these needs, neuronal synaptic terminals contain a greater number of mitochondria than other cellular regions $[3,36]$. Both docked and motile mitochondria are present at presynaptic sites to provide ATP and influence synaptic vesicle release [59]. Mitochondrial disruption at the synapse has been well documented in multiple models of neurodegenerative diseases and commonly appears to be a consequence of increased cellular stress [35]. In the case of Alzheimer's disease, numerous in vitro and in vivo studies have now reported disruption to the trafficking, dynamics and proteome of these organelles [7, 18, 24, $32,57]$.
In recent years, it has been recognised that pathological forms of both $\mathrm{A} \beta$ and tau may play a role in these disruptions $[34,50]$. In the present study, using post-mortem human brain tissue from individuals with AD pathology and control tissue, a region-specific depletion in the proportion of presynaptic terminals containing multiple mitochondria was observed in the diseased state. This reduction was detected in BA41/42 tissue from individuals with Alzheimer's disease, whilst BA46 appeared resistant to this loss. The current study suggests a selective vulnerability of BA41/42 synapses to mitochondrial depletion. Temporal cortex has previously been reported to be particularly vulnerable to deficits in complex IV of the mitochondrial respiratory chain in comparison with frontal cortex in individuals with Alzheimer's disease [39].

A possible explanation for this reduction in mitochondria may be a result of disrupted anterograde transport. Axonal transport defects have been widely reported in culture models of $\mathrm{AD}$, with several studies indicating that the pathological forms of A $\beta$, APP, PS1 and tau can all affect fast axonal transport [13, 25, 26, 48]. For example, application of $A \beta$ fragments and oligomers in cultured hippocampal neurons have been shown to reduce the proportion of mitochondria capable of moving towards the synapse in an NMDA receptor-dependent mechanism $[9,25]$. However, such studies utilise non-physiological, higher levels of amyloid beta, which may contribute to the reported deficits. Pathological forms of tau have also been proposed to inhibit anterograde transport via different mechanisms $[13,16,57]$. However, it has been suggested that the reported tau-mediated disruptions may be a consequence of tau overexpression and that tau may only interfere with trafficking when it is present at high levels. Therefore, in the present study we analysed the number of presynaptic mitochondria present in human brain tissue with AD pathology in the absence of exogenous overexpression systems. Taken together, deficits in the recruitment and redistribution of mitochondria to presynaptic terminals in $\mathrm{AD}$ may be responsible for the reduced mitochondrial accumulation observed in BA41/42 pre-synapses. Similar alterations in mitochondrial localisation have also been reported in human $\mathrm{AD}$ neurons that contain aggregates of misfolded tau, suggesting that soluble forms of tau may have negative consequences on the cellular distribution of mitochondria [32].

An alternative explanation for the observed decrease in the percentage of pre-synapses with multiple mitochondria in BA41/42 could be due to alterations in mitochondrial morphology. Previous studies have reported alterations in the ultrastructure of mitochondria under pathological conditions including swelling of these organelles [6, 43]. In the presence of $A \beta$, an exacerbation in the opening of the mitochondrial permeability transition pore (mPTP) has been reported $[42,43]$. The resulting increase in the permeability of the inner mitochondrial membrane leads 

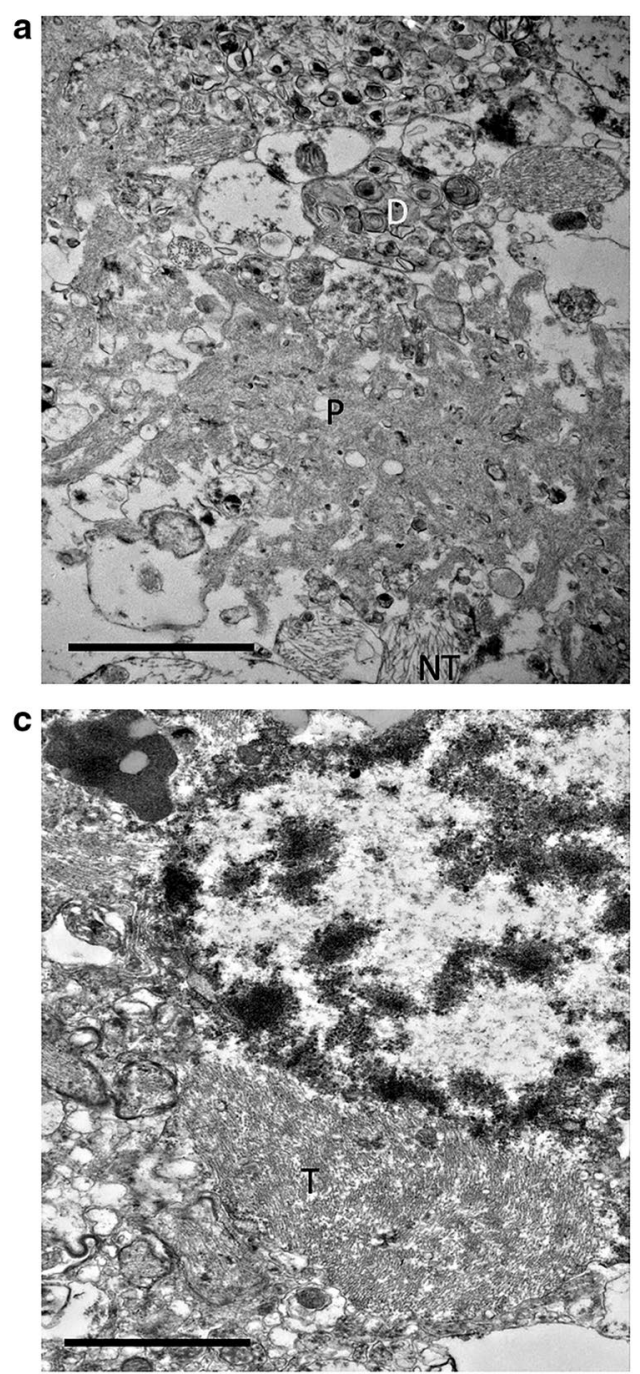

Fig. 5 Fibrils in amyloid plaques and neurofibrillary tangles are observed in tissue from Alzheimer's disease cases with TEM. A $\beta$ plaques (P) surrounded by dystrophic neurites (D) and neuropil threads (NT) are detected in the neuropil from tissue derived from

to the influx of fluid and an increase in mitochondrial size which has previously been reported in response to $\mathrm{A} \beta$ [45]. The presence of larger mitochondria may occupy space within presynaptic sites preventing further docking of mitochondria at this location. Altered fission or fusion of mitochondria in AD could also contribute to our observed change in presynaptic terminals containing multiple mitochondria. There is evidence supporting altered mitochondrial dynamics in many neurodegenerative diseases including $\mathrm{AD}$ [4]. A further explanation for a reduction in mitochondria present at presynaptic sites could be accounted for by an increase in mitochondrial turnover by mitophagy. Previous studies in AD patient brains have reported autophagic accumulation of mitochondria suggestive of enhanced mitophagy induction $[23,44]$.
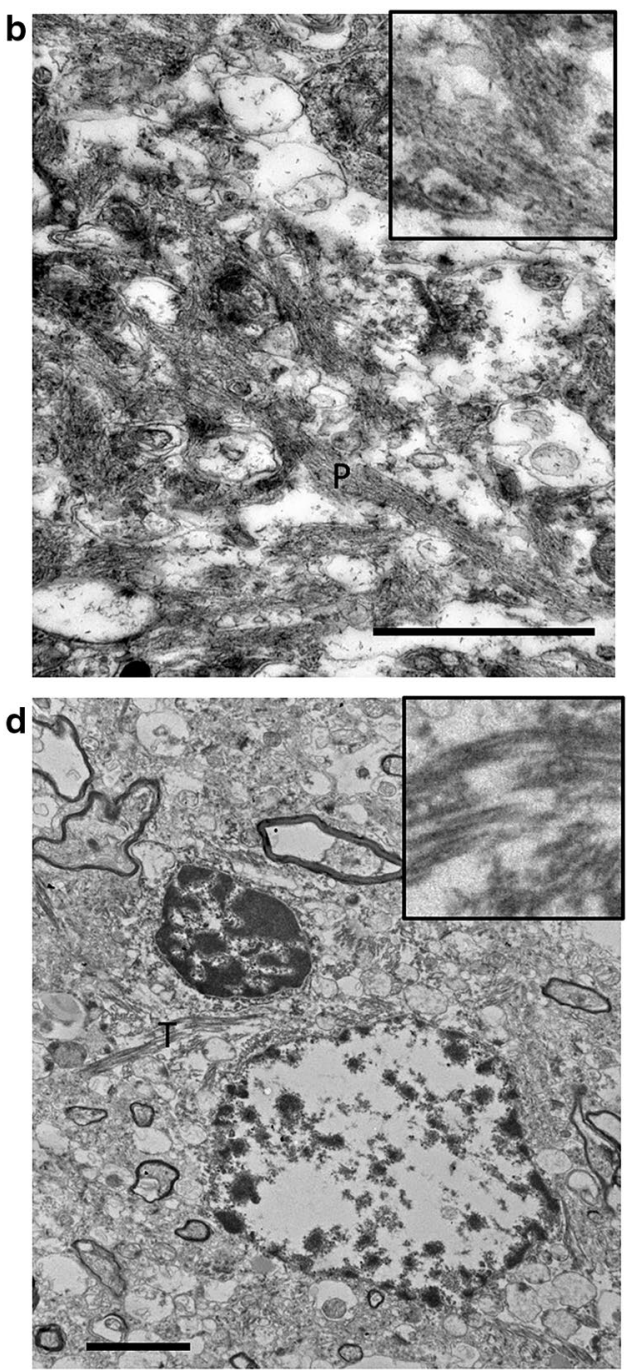

AD cases $(\mathbf{a}, \mathbf{b})$. NFT are observed around the soma of neurons from AD tissue (labeled T in $\mathbf{c}, \mathbf{d}$ ). Scale bar represents $2 \mu \mathrm{m}$ in $\mathbf{a}, \mathbf{c}$, and $\mathbf{d}$; $1 \mu \mathrm{m}$ in b , inset $500 \mathrm{~nm} \times 500 \mathrm{~nm}$ in $\mathbf{b}, 1000 \times 1000 \mathrm{~nm}$ in $\mathbf{d}$

Under stress conditions such as hypoxia-reoxygenation, mitochondrial uncoupling and complex inhibition, additional morphologies such as donut, cup and blob have been reported in cells, mice, primates and humans [1, 21, 37, 61]. One study in aged Rhesus monkeys suggested that these morphological changes also appear to accompany functional changes; working memory in these monkeys appeared to correlate positively with straight mitochondria and inversely with donut mitochondria in the presynaptic boutons of dorsal lateral prefrontal cortex (dlPFC). It has been suggested that donut mitochondria are markers of early cellular stress [1, 38]; however, these O-shaped and cup-shaped (' $\mathrm{C}$ ' and ' $\mathrm{U}$ ' shaped) organelles have been observed not only in pathological tissue [12] but in healthy tissue also [17]. Whether these forms are present in the 
Alzheimer's diseased brain has yet to be ascertained. In this study, we did not perform 3D reconstructions of all of the synapses studied, so we cannot draw firm conclusions about mitochondrial morphology, but we did observe mitochondrial profiles in single sections that had abnormal morphology.

The maintenance of a pool of mitochondria at AD synapses from BA46 may reflect the resistance of mitochondria from this brain region to the toxic effects of $A \beta$ and tau. Growing evidence suggests that prefrontal synapses remain relatively intact until later stages of the disease as a result of trophic effects that partially compensate for the early phases of degeneration [41]. Whether this support applies to the maintenance of synaptic mitochondria is not known, but may account for a maintained population in this brain region. However, in the present study, latestage AD brains were examined; therefore, this compensatory protection from synaptic loss maybe ineffective by this stage of disease. It must also be recognised that the synapses sampled consist of those that remain at the end stages of the disease process. Consequently, these synapses may themselves be more resilient to pathological changes. It could be possible that mitochondrial changes at the synapse may be more visible in moderate stages of the disease where synapses remain prior to extensive degeneration and loss.

Our previous data indicate synapse shrinkage in the immediate vicinity of plaques in BA41/42, and the accumulation of oligomeric $A \beta$ and phosphorylated tau within synapses [31]. Here, we did not observe any change in the length of the PSD opposed to the presynaptic terminal; however, there were not enough plaques in the small EM samples to perform the analogous study to our previous work using the higher throughput array tomography technique. The lack of synapse shrinkage when looking both near and far from plaques is in agreement with a recent study using threedimensional EM which revealed that many morphological features of remaining synapses in $\mathrm{AD}$ transentorhinal cortex remain unchanged despite global loss of synapses [14]. The absence of fibrils in pre- and post-synaptic terminals supports previous work strongly implicating soluble but not fibrillar forms of $\mathrm{A} \beta$ and tau in synapse toxicity $[47,55]$. In addition to occasional mitochondria with abnormal pathology, we observed multivesicular bodies in a small subset of post-synaptic terminals, which is interesting in light of the role they play in the secretion of $A \beta$ [49].

Together, these data indicate that synaptic mitochondria are reduced in presynaptic terminals in $\mathrm{AD}$ in a region-specific manner. The more pronounced effect in presynaptic terminals and a lack of change in the presence of mitochondria in post-synapses support the notion that axonal transport of mitochondria at long distances to synaptic terminals is impaired in vulnerable brain regions in $\mathrm{AD}$.
Acknowledgements We wish to thank all of our patient donors and their families for their valuable contributions to this work. This work was supported by funding provided by Alzheimer's Society, the UK Dementia Research Institute, European Research Council (ALZSYN), Alzheimer's Research UK and the Scottish Government and a University of Edinburgh Wellcome Trust ISSF. We thank Prof Marian DiFiglia and the Philly Dake Electron Microscopy Centre at Massachusetts General Hospital for access to TEM facilities. This paper is in memory of Dr. Will Stoothoff who contributed to the ideas leading to the experiments.

Open Access This article is distributed under the terms of the Creative Commons Attribution 4.0 International License (http://creativeco mmons.org/licenses/by/4.0/), which permits unrestricted use, distribution, and reproduction in any medium, provided you give appropriate credit to the original author(s) and the source, provide a link to the Creative Commons license, and indicate if changes were made.

\section{References}

1. Ahmad T, Aggarwal K, Pattnaik B, Mukherjee S, Sethi T, Tiwari BK, Kumar M, Micheal A, Mabalirajan U, Ghosh B et al (2013) Computational classification of mitochondrial shapes reflects stress and redox state. Cell Death Dis 4:e461. https://doi. org/10.1038/cddis.2012.213

2. Baddeley AD, Bressi S, Della Sala S, Logie R, Spinnler H (1991) The decline of working memory in Alzheimer's disease. A longitudinal study. Brain 114(Pt 6):2521-2542

3. Bogan N, Cabot JB (1991) Light and electron microscopic analyses of intraspinal axon collaterals of sympathetic preganglionic neurons. Brain Res 541:241-251

4. Burte F, Carelli V, Chinnery PF, Yu-Wai-Man P (2015) Disturbed mitochondrial dynamics and neurodegenerative disorders. Nat Rev Neurol 11:11-24. https://doi.org/10.1038/nrneurol.2014.228

5. Calkins MJ, Reddy PH (2011) Amyloid beta impairs mitochondrial anterograde transport and degenerates synapses in Alzheimer's disease neurons. Biochim Biophys Acta 1812:507-513. https://doi.org/10.1016/j.bbadis.2011.01.007

6. Chen JX, Yan SS (2010) Role of mitochondrial amyloid-beta in Alzheimer's disease. J Alzheimers Dis 20(Suppl 2):S569-S578. https://doi.org/10.3233/JAD-2010-100357

7. Chou JL, Shenoy DV, Thomas N, Choudhary PK, Laferla FM, Goodman SR, Breen GA (2011) Early dysregulation of the mitochondrial proteome in a mouse model of Alzheimer's disease. J Proteom 74:466-479. https://doi.org/10.1016/j.jprot.2010.12.012

8. David DC, Hauptmann S, Scherping I, Schuessel K, Keil U, Rizzu P, Ravid R, Drose S, Brandt U, Muller WE et al (2005) Proteomic and functional analyses reveal a mitochondrial dysfunction in P301L tau transgenic mice. J Biol Chem 280:23802-23814. https://doi.org/10.1074/jbc.M500356200

9. Decker H, Lo KY, Unger SM, Ferreira ST, Silverman MA (2010) Amyloid-beta peptide oligomers disrupt axonal transport through an NMDA receptor-dependent mechanism that is mediated by glycogen synthase kinase 3beta in primary cultured hippocampal neurons. J Neurosci 30:9166-9171. https://doi.org/10.1523/ JNEUROSCI.1074-10.2010

10. DeKosky ST, Scheff SW (1990) Synapse loss in frontal cortex biopsies in Alzheimer's disease: correlation with cognitive severity. Ann Neurol 27:457-464. https://doi.org/10.1002/ana.41027 0502 
11. DeKosky ST, Scheff SW, Styren SD (1996) Structural correlates of cognition in dementia: quantification and assessment of synapse change. Neurodegeneration 5:417-421

12. Ding WX, Li M, Biazik JM, Morgan DG, Guo F, Ni HM, Goheen M, Eskelinen EL, Yin XM (2012) Electron microscopic analysis of a spherical mitochondrial structure. J Biol Chem 287:4237342378. https://doi.org/10.1074/jbc.M112.413674

13. Dixit R, Ross JL, Goldman YE, Holzbaur EL (2008) Differential regulation of dynein and kinesin motor proteins by tau. Science 319:1086-1089. https://doi.org/10.1126/science.1152993

14. Dominguez-Alvaro M, Montero-Crespo M, Blazquez-Llorca L, Insausti R, DeFelipe J, Alonso-Nanclares L (2018) Three-dimensional analysis of synapses in the transentorhinal cortex of Alzheimer's disease patients. Acta Neuropathol Commun 6:20. https ://doi.org/10.1186/s40478-018-0520-6

15. Drubin D, Kobayashi S, Kirschner M (1986) Association of tau protein with microtubules in living cells. Ann N Y Acad Sci 466:257-268

16. Ebneth A, Godemann R, Stamer K, Illenberger S, Trinczek B, Mandelkow E (1998) Overexpression of tau protein inhibits kinesin-dependent trafficking of vesicles, mitochondria, and endoplasmic reticulum: implications for Alzheimer's disease. J Cell Biol 143:777-794

17. Ghadially FN (1997) Ultrastructural pathology of the cell and matrix. Butterworth-Heinemann, Oxford

18. Gillardon F, Rist W, Kussmaul L, Vogel J, Berg M, Danzer K, Kraut N, Hengerer B (2007) Proteomic and functional alterations in brain mitochondria from $\mathrm{Tg} 2576$ mice occur before amyloid plaque deposition. Proteomics 7:605-616. https://doi.org/10.1002/ pmic. 200600728

19. Gillingwater TH, Ingham CA, Parry KE, Wright AK, Haley JE, Wishart TM, Arbuthnott GW, Ribchester RR (2006) Delayed synaptic degeneration in the CNS of Wlds mice after cortical lesion. Brain 129:1546-1556. https://doi.org/10.1093/brain/awl101

20. Graham LC, Eaton SL, Brunton PJ, Atrih A, Smith C, Lamont DJ, Gillingwater TH, Pennetta G, Skehel P, Wishart TM (2017) Proteomic profiling of neuronal mitochondria reveals modulators of synaptic architecture. Mol Neurodegener 12:77. https://doi. org/10.1186/s13024-017-0221-9

21. Hara Y, Yuk F, Puri R, Janssen WG, Rapp PR, Morrison JH (2014) Presynaptic mitochondrial morphology in monkey prefrontal cortex correlates with working memory and is improved with estrogen treatment. Proc Natl Acad Sci USA 111:486-491. https://doi.org/10.1073/pnas.1311310110

22. Hauptmann S, Scherping I, Drose S, Brandt U, Schulz KL, Jendrach M, Leuner K, Eckert A, Muller WE (2009) Mitochondrial dysfunction: an early event in Alzheimer pathology accumulates with age in AD transgenic mice. Neurobiol Aging 30:1574-1586. https://doi.org/10.1016/j.neurobiolaging.2007.12.005

23. Hirai I, Wang HG (2001) Survival-factor-induced phosphorylation of Bad results in its dissociation from Bcl-x(L) but not Bcl-2. Biochem J 359:345-352

24. Hirai K, Aliev G, Nunomura A, Fujioka H, Russell RL, Atwood CS, Johnson AB, Kress Y, Vinters HV, Tabaton M et al (2001) Mitochondrial abnormalities in Alzheimer's disease. J Neurosci 21:3017-3023

25. Hiruma $\mathrm{H}$, Katakura $\mathrm{T}$, Takahashi $\mathrm{S}$, Ichikawa $\mathrm{T}$, Kawakami $\mathrm{T}$ (2003) Glutamate and amyloid beta-protein rapidly inhibit fast axonal transport in cultured rat hippocampal neurons by different mechanisms. J Neurosci 23:8967-8977

26. Ishihara T, Hong M, Zhang B, Nakagawa Y, Lee MK, Trojanowski JQ, Lee VM (1999) Age-dependent emergence and progression of a tauopathy in transgenic mice overexpressing the shortest human tau isoform. Neuron 24:751-762
27. Ittner LM, Gotz J (2011) Amyloid-beta and tau-a toxic pas de deux in Alzheimer's disease. Nat Rev Neurosci 12:65-72. https ://doi.org/10.1038/nrn2967

28. Kanaan NM, Morfini GA, LaPointe NE, Pigino GF, Patterson KR, Song Y, Andreadis A, Fu Y, Brady ST, Binder LI (2011) Pathogenic forms of tau inhibit kinesin-dependent axonal transport through a mechanism involving activation of axonal phosphotransferases. J Neurosci 31:9858-9868. https://doi.org/10.1523/ JNEUROSCI.0560-11.2011

29. Kay KR, Smith C, Wright AK, Serrano-Pozo A, Pooler AM, Koffie R, Bastin ME, Bak TH, Abrahams S, Kopeikina KJ et al (2013) Studying synapses in human brain with array tomography and electron microscopy. Nat Protoc 8:1366-1380. https://doi. org/10.1038/nprot.2013.078

30. Keil U, Bonert A, Marques CA, Scherping I, Weyermann J, Strosznajder JB, Muller-Spahn F, Haass C, Czech C, Pradier L et al (2004) Amyloid beta-induced changes in nitric oxide production and mitochondrial activity lead to apoptosis. J Biol Chem 279:50310-50320. https://doi.org/10.1074/jbc.M405600200

31. Koffie RM, Hashimoto T, Tai HC, Kay KR, Serrano-Pozo A, Joyner D, Hou S, Kopeikina KJ, Frosch MP, Lee VM et al (2012) Apolipoprotein E4 effects in Alzheimer's disease are mediated by synaptotoxic oligomeric amyloid-beta. Brain 135:2155-2168. https://doi.org/10.1093/brain/aws127

32. Kopeikina KJ, Carlson GA, Pitstick R, Ludvigson AE, Peters A, Luebke JI, Koffie RM, Frosch MP, Hyman BT, Spires-Jones TL (2011) Tau accumulation causes mitochondrial distribution deficits in neurons in a mouse model of tauopathy and in human Alzheimer's disease brain. Am J Pathol 179:2071-2082. https:// doi.org/10.1016/j.ajpath.2011.07.004

33. LaPointe NE, Morfini G, Pigino G, Gaisina IN, Kozikowski AP, Binder LI, Brady ST (2009) The amino terminus of tau inhibits kinesin-dependent axonal transport: implications for filament toxicity. J Neurosci Res 87:440-451. https://doi.org/10.1002/ jnr.21850

34. Lasagna-Reeves CA, Castillo-Carranza DL, Sengupta U, Clos AL, Jackson GR, Kayed R (2011) Tau oligomers impair memory and induce synaptic and mitochondrial dysfunction in wild-type mice. Mol Neurodegener 6:39. https://doi.org/10.1186/1750-1326-6-39

35. Lezi E, Swerdlow RH (2012) Mitochondria in neurodegeneration. Adv Exp Med Biol 942:269-286. https://doi. org/10.1007/978-94-007-2869-1_12

36. Li Z, Okamoto K, Hayashi Y, Sheng M (2004) The importance of dendritic mitochondria in the morphogenesis and plasticity of spines and synapses. Cell 119:873-887. https://doi.org/10.1016/j. cell.2004.11.003

37. Liu X, Hajnoczky G (2011) Altered fusion dynamics underlie unique morphological changes in mitochondria during hypoxiareoxygenation stress. Cell Death Differ 18:1561-1572. https://doi. org/10.1038/cdd.2011.13

38. Long Q, Zhao D, Fan W, Yang L, Zhou Y, Qi J, Wang X, Liu X (2015) Modeling of mitochondrial donut formation. Biophys J 109:892-899. https://doi.org/10.1016/j.bpj.2015.07.039

39. Maurer I, Zierz S, Moller HJ (2000) A selective defect of cytochrome c oxidase is present in brain of Alzheimer disease patients. Neurobiol Aging 21:455-462

40. McInnes J, Wierda K, Snellinx A, Bounti L, Wang YC, Stancu IC, Apostolo N, Gevaert K, Dewachter I, Spires-Jones TL et al (2018) Synaptogyrin-3 mediates presynaptic dysfunction induced by tau. Neuron 97(823-835):e828. https://doi.org/10.1016/j.neuro n.2018.01.022

41. Minger SL, Honer WG, Esiri MM, McDonald B, Keene J, Nicoll JA, Carter J, Hope T, Francis PT (2001) Synaptic pathology in prefrontal cortex is present only with severe dementia in Alzheimer disease. J Neuropathol Exp Neurol 60:929-936 
42. Moreira PI, Santos MS, Moreno A, Oliveira C (2001) Amyloid beta-peptide promotes permeability transition pore in brain mitochondria. Biosci Rep 21:789-800

43. Moreira PI, Santos MS, Moreno A, Rego AC, Oliveira C (2002) Effect of amyloid beta-peptide on permeability transition pore: a comparative study. J Neurosci Res 69:257-267. https://doi. org/10.1002/jnr.10282

44. Moreira PI, Siedlak SL, Wang X, Santos MS, Oliveira CR, Tabaton M, Nunomura A, Szweda LI, Aliev G, Smith MA et al (2007) Increased autophagic degradation of mitochondria in Alzheimer disease. Autophagy 3:614-615

45. Mungarro-Menchaca X, Ferrera P, Moran J, Arias C (2002) betaAmyloid peptide induces ultrastructural changes in synaptosomes and potentiates mitochondrial dysfunction in the presence of ryanodine. J Neurosci Res 68:89-96. https://doi.org/10.1002/jnr.10193

46. Pickett EK, Henstridge CM, Allison E, Pitstick R, Pooler A, Wegmann S, Carlson G, Hyman BT, Spires-Jones TL (2017) Spread of tau down neural circuits precedes synapse and neuronal loss in the rTgTauEC mouse model of early Alzheimer's disease. Synapse. https://doi.org/10.1002/syn.21965

47. Pickett EK, Koffie RM, Wegmann S, Henstridge CM, Herrmann AG, Colom-Cadena M, Lleo A, Kay KR, Vaught M, Soberman $R$ et al (2016) Non-fibrillar oligomeric amyloid-beta within synapses. J Alzheimers Dis 53:787-800. https://doi.org/10.3233/ JAD-160007

48. Pigino G, Morfini G, Pelsman A, Mattson MP, Brady ST, Busciglio J (2003) Alzheimer's presenilin 1 mutations impair kinesinbased axonal transport. J Neurosci 23:4499-4508

49. Rajendran L, Honsho M, Zahn TR, Keller P, Geiger KD, Verkade P, Simons K (2006) Alzheimer's disease beta-amyloid peptides are released in association with exosomes. Proc Natl Acad Sci USA 103:11172-11177. https://doi.org/10.1073/pnas.0603838103

50. Reddy PH, Beal MF (2008) Amyloid beta, mitochondrial dysfunction and synaptic damage: implications for cognitive decline in aging and Alzheimer's disease. Trends Mol Med 14:45-53. https ://doi.org/10.1016/j.molmed.2007.12.002

51. Rhein V, Song X, Wiesner A, Ittner LM, Baysang G, Meier F, Ozmen L, Bluethmann H, Drose S, Brandt U et al (2009) Amyloid-beta and tau synergistically impair the oxidative phosphorylation system in triple transgenic Alzheimer's disease mice. Proc Natl Acad Sci USA 106:20057-20062. https://doi.org/10.1073/ pnas.0905529106

52. Rui Y, Tiwari P, Xie Z, Zheng JQ (2006) Acute impairment of mitochondrial trafficking by beta-amyloid peptides in hippocampal neurons. J Neurosci 26:10480-10487. https://doi.org/10.1523/ JNEUROSCI.3231-06.2006
53. Rui Y, Zheng JQ (2016) Amyloid beta oligomers elicit mitochondrial transport defects and fragmentation in a time-dependent and pathway-specific manner. Mol Brain 9:79. https://doi.org/10.1186/ s13041-016-0261-z

54. Serrano-Pozo A, Frosch MP, Masliah E, Hyman BT (2011) Neuropathological alterations in Alzheimer disease. Cold Spring Harb Perspect Med. https://doi.org/10.1101/cshperspect.a006189

55. Spires-Jones TL, Hyman BT (2014) The intersection of amyloid beta and tau at synapses in Alzheimer's disease. Neuron 82:756771. https://doi.org/10.1016/j.neuron.2014.05.004

56. Stokin GB, Lillo C, Falzone TL, Brusch RG, Rockenstein E, Mount SL, Raman R, Davies P, Masliah E, Williams DS et al (2005) Axonopathy and transport deficits early in the pathogenesis of Alzheimer's disease. Science 307:1282-1288. https://doi. org/10.1126/science.1105681

57. Stoothoff W, Jones PB, Spires-Jones TL, Joyner D, Chhabra E, Bercury K, Fan Z, Xie H, Bacskai B, Edd J et al (2009) Differential effect of three-repeat and four-repeat tau on mitochondrial axonal transport. J Neurochem 111:417-427. https://doi.org/10.1 111/j.1471-4159.2009.06316.x

58. Stopford CL, Thompson JC, Neary D, Richardson AM, Snowden JS (2012) Working memory, attention, and executive function in Alzheimer's disease and frontotemporal dementia. Cortex 48:429_ 446. https://doi.org/10.1016/j.cortex.2010.12.002

59. Sun T, Qiao H, Pan PY, Chen Y, Sheng ZH (2013) Motile axonal mitochondria contribute to the variability of presynaptic strength. Cell Rep 4:413-419. https://doi.org/10.1016/j.celrep.2013.06.040

60. Terry RD, Masliah E, Salmon DP, Butters N, DeTeresa R, Hill R, Hansen LA, Katzman R (1991) Physical basis of cognitive alterations in Alzheimer's disease: synapse loss is the major correlate of cognitive impairment. Ann Neurol 30:572-580

61. Vincent AE, Ng YS, White K, Davey T, Mannella C, Falkous G, Feeney C, Schaefer AM, McFarland R, Gorman GS et al (2016) The spectrum of mitochondrial ultrastructural defects in mitochondrial myopathy. Sci Rep 6:30610. https://doi.org/10.1038/ srep30610

62. Vos M, Lauwers E, Verstreken P (2010) Synaptic mitochondria in synaptic transmission and organization of vesicle pools in health and disease. Front Synaptic Neurosci 2:139. https://doi. org/10.3389/fnsyn.2010.00139

63. Zhou L, McInnes J, Wierda K, Holt M, Herrmann AG, Jackson RJ, Wang YC, Swerts J, Beyens J, Miskiewicz K et al (2017) Tau association with synaptic vesicles causes presynaptic dysfunction. Nat Commun 8:15295. https://doi.org/10.1038/ncomms15295 